Pak. j. sci. ind. res. Ser. B: biol. sci. 2017 60(2) 80-86

\title{
DPPH Radical Scavenging Assay, Biological Activities, Nutritional Composition and Quality Parameters of Momordica charantia Seeds Grown in District Charsadda, KPK, Pakistan
}

\author{
Fazia Ghaffar ${ }^{a *}$, Bushra Kainat ${ }^{a}$, Hamid Ullah Shah ${ }^{\mathrm{b}}$ and Inayat Ur Rahman ${ }^{\mathrm{c}}$ \\ ${ }^{a}$ Department of Food \& Nutrition Sciences, College of Home Economics, University of Peshawar, \\ Peshawar, Pakistan \\ ${ }^{b}$ Department of Agricultural Chemistry, KPK Agricultural University, Peshawar, Pakistan \\ ${ }^{c}$ Medicinal Botanic Center (MBC), PCSIR Laboratories Complex, Peshawar-25100, Pakistan
}

(received January 19, 2016; revised October 26, 2016; accepted October 28, 2016)

\begin{abstract}
The nutritional composition, physicochemical characteristics, antimicrobial activity and DPPH free radical scavenging activity of the oil extracted and proximate and elemental composition of seed cake of the local variety of Momordica charantia were examined as per AOAC or elsewhere mentioned procedures. Physicochemical properties of the oil exhibited colour $(1.71 \mathrm{R} / \mathrm{U}, 1.19 \mathrm{Y} / \mathrm{U})$ being reddish brown, the higher iodine value (105.5), saponification value (190.7), low acid value (1.3) and the higher proportion of unsaturated fatty acids (especially the omega-3 fatty acid) as compared to saturated fatty acids of the oil are an indication of its edibility and industrial utility. The oil also showed good inhibitory action against the selected fungal and bacterial strains as well as DPPH free radical scavenging activity. Results of the proximate composition of the seed cake showed it to be good source of total proteins (18. $17 \%)$, crude fibre $10.37 \%$, percent oil (38.1\%) and elements such as calcium (374.9 mg/100 g), copper $(3.01 \mathrm{mg} / 100 \mathrm{~g})$, iron $(39.57 \mathrm{mg} / 100 \mathrm{~g})$ and zinc $(12.04 \mathrm{mg} / 100 \mathrm{~g})$. It can be concluded from the study that oil and seed cake of the local variety of bitter gourd seed (BGS) oil possesses a good nutritional, antioxidant and antimicrobial potential.
\end{abstract}

Keywords: Momordica charantia, bitter gourd seed, physicochemical properties, fatty acid, antimicrobial potential

\section{Introduction}

Momordica charantia belonging to the Curcurbitaceae family and commonly known as bitter gourd, is a vegetable crop cultivated in humid subtropical regions of the globe (Lucas et al., 2010). It is a commonly grown vegetable in Pakistan and is being used as a cure in diabetes mellitus and other therapeutic evidences. Bitter ground is an effective antidiabetic, anticancer, antimicrobial, anti- hepatotoxic, antiviral, antiulcerogenic having an antioxidant and larvicidal properties (Tuan et al., 2011).

Different parts of the plant are used and the seed is found being a rich source of oil (18.1-37.6\%) and protein (28-30\%). The protein of the seed has been found to be a good source of essential amino acids which can be utilized as a good functional ingredient in food systems. The seed also supply important dietary minerals such as $\mathrm{P}, \mathrm{K}, \mathrm{MG}, \mathrm{S}$, and $\mathrm{Ca}$, along with a variety of flavonoids, phenolic compounds and other antioxidants (Horax et al., 2010).

*Author for correspondence; E-mail: faziaghaffar@upesh.edu.pk
Momordica charantia seed oil possesses many essential nutrient compounds needed for proper functioning of human body. The oil extracted from the seed contain appreciable amount of conjugated linoleic acid and áeleostearic acid which may be of help in reducing the risk of coronary heart diseases in non-diabetic as well as diabetic patients. It not only inhibits pathogenesis and replication of psoriasis but leukemia and cancer as well. The oil also has a utility in paint industries (Ahmad and Khan, 2013).

The present study aimed to assess the physicochemical properties, antioxidant and antimicrobial potential of the BGS oil and nutritional composition of bitter gourd seed cake/flour from the BG (bitter gourd) cultivar commonly grown in district Charsadda, KPK, Pakistan.

\section{Materials and Methods}

Procurement of bitter gourd seeds (BGS). Ripened fruits of a local variety (district Charsadda) were purchased from the local vegetable market. The seeds were separated and were washed several times with 
water to remove any plant and foreign material. Later the seeds were dried in an electric oven until constant weight was achieved. The dried seeds were stored in airtight jars in triplicates for further analyses.

Oil extraction. Dried seeds were grinded in an electric grinder. The ground seed powder was soaked in $n$ hexane for $24 \mathrm{~h}$. After soaking for a day the extract was filtered through filter paper and was then concentrated /distilled in rotary evaporator under reduced pressure at $40-45^{\circ} \mathrm{C}$. Percent oil was calculated and the oil and cake were directly used for quality parameters.

Proximate composition and mineral content determination. After oil extraction the seed cake/residue/flour samples were tested for proximate and elemental composition. By using AOAC official methods (1990) total protein content of the seed cake was estimated by a micro Kjedlhal apparatus. Crude oil was estimated by Soxhlet method while crude fibre and ash contents were determined by the AOAC official methods (1984). For minerals analysis samples were first subjected to acid digestion and later were analysed by atomic absorption spectrophotometer (AAS) methods (AOAC, 2005).

Oil analysis. The physical and chemical parameters of the crude oil were determined as per AOAC official methods (AOAC, 2005). Refractive index, density, specific gravity, surface tension, acid value, free fatty acid value, saponification value, iodine value, colour and peroxide value were carried out.

Fatty acids analysis. Preparation of FAMES. About 25-40 mg of oil sample were weighed in FAMEs tubes and $1.5 \mathrm{~mL}$ methanolic sodium hydroxide $(0.5 \mathrm{~N})$ was added. The tubes were stoppered with screw capes. The mixture was heated in a boiling water bath for $05 \mathrm{~min}$. Tubes were cooled to room temperature and $2.5 \mathrm{~mL}$ $\mathrm{BF}_{3}(10 \%$ in $\mathrm{MeOH})$ was added. Tubes were again heated in boiling water for half an hour. Cooled at room temperature and $5 \mathrm{~mL}$ brine solution $+1 \mathrm{~mL} n$-hexane was added. The tubes were shaken vigorously on vortex and then the layers were allowed to separate. The upper (hexane) layer was taken through pasture pipette. For GCMS analysis about $1 \mathrm{~mL} n$-hexane was added again to repeat the above steps to separate the hexane layer. The volume was adjusted to $2 \mathrm{~mL}$, filtered through $45 \mu \mathrm{m}$ membrane filter and transferred to $\mathrm{GC}$ vial for injection into GC-MS.
Identification of fatty acids by GC-MS. The methyl esters of the oil were analysed for the respective fatty acid composition by gas chromatography mass spectrometry. The equipment used for this purpose was Shimadzu GC-MS- QP 2010 plus using a capillary column TRB FFAP (30 m x $0.25 \mathrm{~mm}$ i.d). The temperature programming of the column oven was set as 50 $220{ }^{\circ} \mathrm{C}$ with rise of $5^{\circ} \mathrm{C} / \mathrm{min}$. Helium was used as the carrier gas and its total flow was adjusted to $77.1 \mathrm{~mL} / \mathrm{min}$ while column flow was $3.29 \mathrm{~mL} / \mathrm{min}$ at split ratio of 20.0. The temperatures of injector, interface and ion source were set at 240,240 and $250{ }^{\circ} \mathrm{C}$, respectively. The peaks were identified by comparison of their retention time with those of the standard methyl esters (FAMEs standard mix, 37 components, Sigma Aldrich) analysed under the same conditions.

Antimicrobial assay. The extracted oil of BG was tested against different strains for anti-infective potential. Antibacterial activity against three gram negative bacteria (Xnythomonas campestris,Proteus mirabilis, Escherichia coli) and one gram positive bacteria(Bacillus cereus) and four pathogenic fungi namely Phythium ultimum, Paecilomyces lilacinus, Rhizopus stolonifer and Tricoderma harzanium were tested. The pure microbial strains were obtained from Agriculture Chemistry Lab, Department of Agricultural Chemistry, KPK Agriculture University Peshawar. Agar well diffusion was used for fungi and streaking method was used for bacteria. The minimal bactericidal (MBC) and fungicidal (MFC) potential as zones of inhibition $(\mathrm{mm})$ were determined at different concentrations $(0.2,0.4,0.5,0.6,0.8 \mathrm{mg} / \mu \mathrm{g})$ of the stock solutions of BGS crude oil in sterile DMSO. Standard drug Amoxicillin and Miconazole were used as positive control while sterile DMSO was used as negative control for the purpose of comparison as per procedure of Sheikh et al. (1995).

Antioxidant activity by DPPH free radical scavenging methods. DPPH radical scavenging activity was performed by following the method of Rauf et al. (2012). About $25 \mathrm{mg}$ of oil was dissolved in distilled methanol and was diluted up to $50 \mathrm{~mL}$. From the stock solution $10,20,40,60,80,100 \mathrm{mg} / \mathrm{mL}$ dilutions were prepared. Of each solution $5 \mathrm{~mL}$ was taken in a test tube to which $1 \mathrm{~mL}$ of $0.01 \mathrm{M}$ of DPPH solution was added. They were kept in dark for test minutes along with a control (5 methanol $+1 \mathrm{~mL}$ DPPH solution). After the incubation for $30 \mathrm{~min}$ the antioxidant activity was measured by 
using Optima UV- visible spectrophotometer at wave length of $517 \mathrm{~nm}$. The experiments were performed in three replicates. Quercetin was taken as a standard for the purpose of comparison. Percent radical scavenging activity was calculated as:

$\% \mathrm{DPPH}=$ control absorbance- extract absorbance $\times$ 100/control absorbance

Statistical analysis. Data collected from the triplicate analyses was analysed for means, standard deviations and one way ANOVA at $\mathrm{P}=<0.05$ level of significance wherever needed.

\section{Results and Discussion}

Proximate and elemental composition. Results of the proximate and elemental composition of the BG seed cake/flour are given in Table 1. The data showed seed cake contained percent moisture $7.43 \%$, crude protein $18.17 \%$, crude fibre $10.37 \%$, ash $4.48 \%$ and total carbohydrates $28.88 \%$, respectively. In contrast to present study Anjum et al. (2013) and Prasantha et al. (2009) reported much higher percent moisture (22.9$29.32 \%$ and $53-79.5 \%$ ), respectively, whereas Ali et al. (2008) and Nayam et al. (2009) recorded moisture level similar to the present study $(7.62,8.20 \% 7.3 \%)$, respectively. These differences may be attributed to genetic or maturity variations of the collected samples. The oil content (given as a percentage to the dry weight) of the sample was $38.1 \%$ which is higher than the values

Table 1. Proximate and elemental composition of bitter gourd seed

\begin{tabular}{lll}
\hline \hline Parameter & Content* & P-Level** \\
\hline Proximate values & & \\
Moisture (w/w \%) & $7.43 \pm 0.23$ & $1.50^{\mathrm{a}}$ \\
Percent oil (w/w \%) & $38.1 \pm 3.03$ & $0.07^{\mathrm{a}}$ \\
Crude protein \% & $18.17 \pm 6.09$ & $0.06^{\mathrm{a}}$ \\
Crude fibre \% & $10.37 \pm 0.26$ & $0.06^{\mathrm{a}}$ \\
Ash \% & $4.48 \pm 0.52$ & $0.08^{\mathrm{a}}$ \\
Carbohydrates \% & $28.88 \pm 2.37$ & $0.14^{\mathrm{a}}$ \\
Minerals (mg/100 mg) & & \\
Calcium & $374.21 \pm 7.99$ & $0.04^{\mathrm{a}}$ \\
Iron & $3.01 \pm 0.08$ & $0.64^{\mathrm{a}}$ \\
Copper & $39.57 \pm 3.84$ & $0.72^{\mathrm{a}}$ \\
Zinc & $12.04 \pm 6.87$ & $0.07^{\mathrm{a}}$ \\
\hline \hline
\end{tabular}

$*=$ values represent means of three replications; $* *=$ numbers carrying same alphabets exhibit non significance at 0.05 levels. reported by Ali et al. (2008) and Nyam et al. (2009) being $19.30 \%$ and $26.00 \%$, respectively. However, the oil content was near to the findings of $41-45 \%$ and $31.51-40.79 \%$ by Islam et al. (2011) and Anjum et al. (2013), respectively. Umamaheshwari and Naik (2013) reported $35 \%$ oil in BGS. The mean of total protein content of the samples was found to be $18.17 \%$ indicating BGS as a rich source of protein. This amount (18.17\%) of the present study was in agreement with the finding of Yuwai et al. (1991) Ali et al. (2008) and Anjum et al. (2013) being $18.02 \%, 18.23-23.36 \%$, and $14.92-$ $19.17 \%$, respectively though Nyam et al. (2009) reported lower protein content $(11.8 \%)$. Total carbohydrates as estimated were $28.88 \%$ which are in agreement with the findings of Anjum et al. (2013), Ali et al. (2008), and Nyam et al. (2009). BG seed cake contained appreciable amount of calcium $(374.21 \mathrm{mg} / 100 \mathrm{~g})$ and copper $(3.01 \mathrm{mg} / 100 \mathrm{~g})$, iron $(39.57 \mathrm{mg} / 100 \mathrm{~g})$ and zinc $(12.04 \mathrm{mg} / 100 \mathrm{~g})$ indicating BGS as a good source of minerals also. Similar results were also reported by Ali et al. (2008), Anjum et al. (2013), and Bakare et al. (2010) while iron and zinc content found in the current study are slightly higher than those studied by Aussubaie and EL-Garawany (2004).

Physicochemical properties of BGS oil. Results of different quality parameter of the oil are presented in Table 2. A slight variation in the density $(1.33 \mathrm{~kg} / \mathrm{mg})$ was found from the findings of Anjum et al. (2013), Ali et al. (2008) and Assubaie and El-Garawary (2004) being $0.9709-0.9978,0.9962$ and $0.9448-0.9605 \mathrm{mg} / \mathrm{mL}$ at $25{ }^{\circ} \mathrm{C}$, respectively. The refractive index of the oil $\left(1.4995\right.$ at $\left.25^{\circ} \mathrm{C}\right)$ is closely related to the values reported as $1.4888,1.485,1.4895$ and 1.480 by Ali et al. (2008); Umamaheshwari and Naik (2013); Prasantha et al. (2009) and Anjum et al. (2013), respectively. The specific gravity of the oil samples was 0.87 . The colour of BGS oil was $1.71 \mathrm{red}$ units $(1 \mathrm{inch} / \mathrm{cell})$ while it was 1.2 yellow unit $(1 \mathrm{inch} / \mathrm{cell})$ indicating the presence of polar substances which can work as anti-oxidative agents. The surface tension (2.33), viscosity (7.0 at $21{ }^{\circ} \mathrm{C}$ ) kinematic viscosity (38.32) lower acid value $(1.3 \mathrm{mg}$ of $\mathrm{KOH} / \mathrm{g})$, the high saponification value $(190.7 \mathrm{mg}$ of $\mathrm{KOH} / \mathrm{g})$ and iodine value $(105.5 \mathrm{~g}$ of $\mathrm{I}_{2} / 100 \mathrm{~g}$ ) indicated the potential uses of the oil in diet and industries. The saponificaion value of the present findings are in agreement with those of Ali et al. (2008) and Prasantha et al. (2009) as 187.0 and as 187.01, respectively. Anjum et al. (2013) also reported iodine value as $184.02-186.09$. The percent free fatty acid of 
$0.7 \mathrm{~g} / 100 \mathrm{~g}$ are similar to the findings of 0.86 and 1.06 as reported by Ali et al. (2008), Umamaheshwari and Naik (2013) and Anjum et al. (2013). Peroxide value

Table 2. Physicochemical characteristics of the BGS oil

\begin{tabular}{|c|c|c|}
\hline Parameters & Content* & P- level \\
\hline Colour (red units) & $1.71 \pm 0.24$ & $2.7^{\mathrm{a} * *}$ \\
\hline Colour (yellow units) & $1.2 \pm 0.81$ & $0.90^{\mathrm{a}}$ \\
\hline Refractive index at $25^{\circ} \mathrm{C}$ & $1.4995 \pm 0.04$ & $0.07^{\mathrm{a}}$ \\
\hline Density $\left(20^{\circ} \mathrm{C} \mathrm{kg} / \mathrm{m}^{3}\right)$ & $1.33 \pm 0.02$ & $0.09^{\mathrm{a}}$ \\
\hline Specific gravity & $0.87 \pm 0.08$ & $0.53^{\mathrm{a}}$ \\
\hline Surface tension & $2.33 \pm 0.081$ & $0.07^{\mathrm{a}}$ \\
\hline Viscosity $\left(21^{\circ} \mathrm{C}\right)$ & $70 \pm 0.47$ & $0.3^{\mathrm{a}}$ \\
\hline Kinematic viscosity $\left(\mathrm{mm}^{2} / \mathrm{sec}\right)$ & $38.32 \pm 0.93$ & $0.28^{\mathrm{a}}$ \\
\hline Acid value (mg KOH/g) & $1.3 \pm 0.21$ & $0.36^{\mathrm{a}}$ \\
\hline Free fatty acid (g/100 g) & $0.7 \pm 0.15$ & $0.14^{\mathrm{a}}$ \\
\hline \multicolumn{3}{|l|}{ Saponification value } \\
\hline (mg KOH/g of oil) & $190.7 \pm 0.5$ & $0.93^{\mathrm{a}}$ \\
\hline Iodine value ( $\mathrm{g}$ of $\mathrm{I}_{2} / 100 \mathrm{~g}$ ) & $105.5 \pm 3.3$ & $0.91^{\mathrm{a}}$ \\
\hline $\begin{array}{l}\text { Peroxide value } \\
\left(\text { meq of } \mathrm{O}_{2} / \mathrm{kg} \text { of oil) }\right.\end{array}$ & $3.1 \pm 0.7$ & $0.04^{\mathrm{a}}$ \\
\hline
\end{tabular}

$*=$ values are means of three replicates; ${ }^{* *}=$ numbers carrying same alphabets exhibit non significance at 0.05 levels. of $3.1 \mathrm{meq} / \mathrm{kg}$ of oil are in agreement with the findings of Anjum et al. (2013). Peroxide value and free fatty acid value are important quality measures of the edible oils.

Fatty acids and percent saturated vs unsaturated fatty acids distribution of the BGS oil. Fatty acid composition of BGS oil is presented in Table 3 and Fig. 1. BGS oil contained appreciable amounts of stearic acid $(66.57 \%)$, oleic acid $(9.76 \%)$ followed by palmitic acid $(0.85 \%)$, linolenic acid $(2.19 \%)$, arachidic acid and behenic acid (1.04\% and $1.93 \%)$, respectively. Similar stearic acid values were reported from the oil of Chinese BGS oil; however, Anjum et al. (2013) reported 29.14\% stearic acid. Ali et al. (2008) also reported lower values for stearic acid, higher values for oleic acid and similar values for palmitic acid. The drastic variation in the fatty acid composition may be attributed to variation in the soil condition, type of variety, and climatic conditions in which the tested BG were grown.

DPPH free radical scavenging potential of BGS oil. DPPH free radical scavenging activity of BGS oil is shown in Fig. 2. Observed scavenging activity $(\mathrm{mg} / \mathrm{mL}$ DPPH scavenging) demonstrated by BGS oil as 23.89,

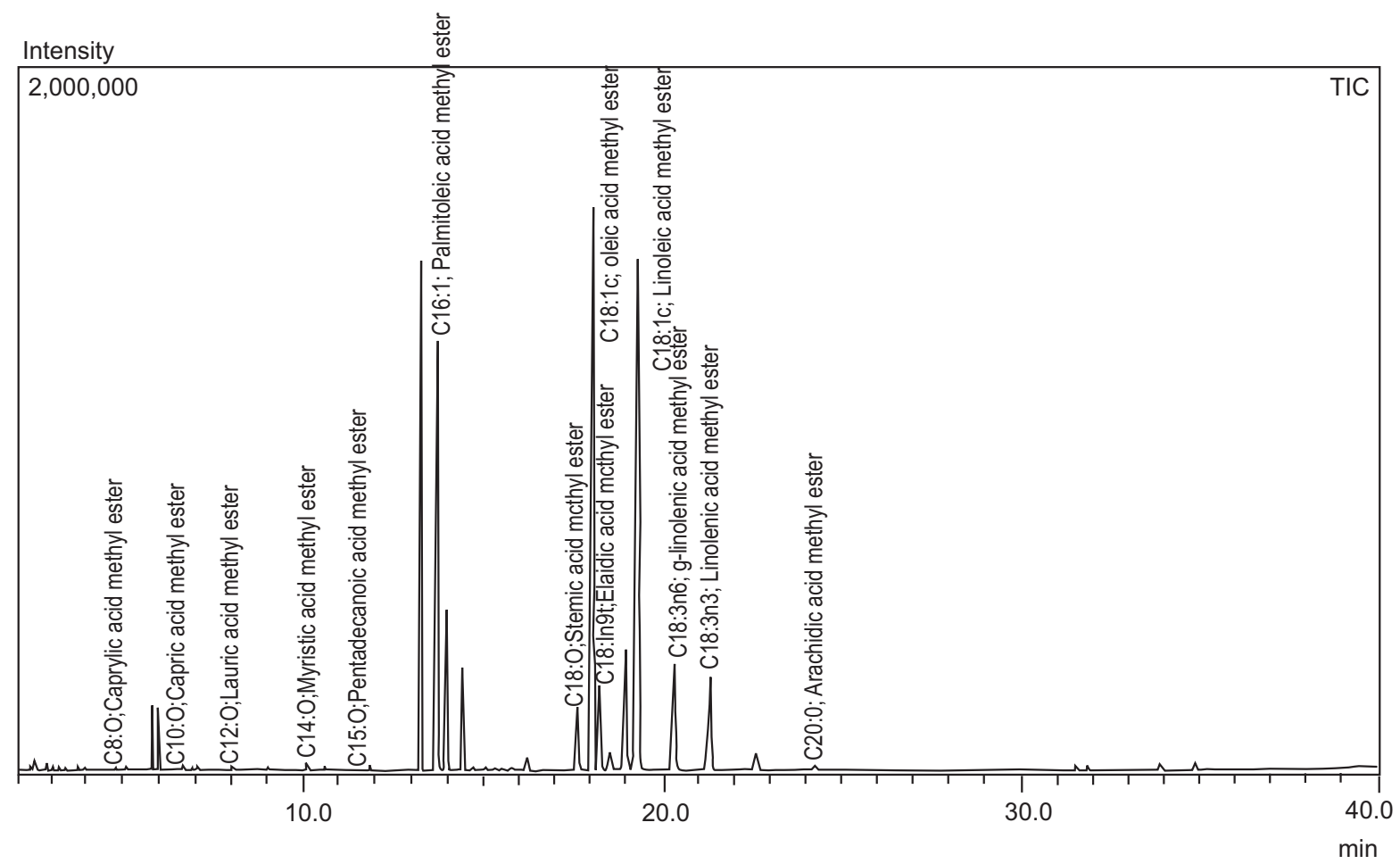

Fig. 1. Chromatogram of BGS oil fatty acids methyl esters. 
Table 3. Fatty acids composition of the BGS oil

\begin{tabular}{ll}
\hline \hline Fatty acids & \%age of concentrations* \\
\hline Caprylic acid $\mathrm{C}_{8}: 0$ & $0.098 \pm 0.03$ \\
Capric acid $\mathrm{C}_{10}: 0$ & $0.05 \pm 0.02$ \\
Lauric acid $\mathrm{C}_{12: 0}: 0.05 \pm 0.015$ \\
Myristic acid $\mathrm{C}_{14: 0}$ & $0.185 \pm 0.52$ \\
Palmitic acid $\mathrm{C}_{16: 0}$ & $4.72 \pm 0.83$ \\
Palmitoleic acid $\mathrm{C}_{16: 1}$ & $0.85 \pm 0.65$ \\
Stearic acid $\mathrm{C}_{18: 0}$ & $66.57 \pm 0.29$ \\
Oleic acid $\mathrm{C}_{18: 1}$ & $9.76 \pm 0.03$ \\
Lenoleic acid $\mathrm{C}_{18: 2}: 24 \pm 0.05$ \\
-Linolenic acid $\mathrm{C}_{18: 3 \mathrm{n} 6}$ & $0.241 .91 \pm 0.92$ \\
Linolenic acid $\mathrm{C}_{18: 3 \mathrm{n} 6}$ & $2.19 \pm 0.06$ \\
Arachidic acid $\mathrm{C}_{20}: 0$ & $1.04 \pm 0.87$ \\
Behenic acid $\mathrm{C}_{22}: 0$ & $1.93 \pm 0.09$ \\
Lignoceric acid $\mathrm{C}_{24}: 0$ & $\mathrm{ND}$ \\
Total saturated acid & $74.43 \pm 0.02$ \\
Total unsaturated acid & $14.94 \pm 0.08$ \\
$18 / 16$ ratio & $14.54 \pm 0.04$ \\
20-24 ratio & $2.97 \pm 0.06$ \\
\hline \hline
\end{tabular}

* = means of triplicate analysis.

$22.16,20.50,19.75,17.86$, and $11.96 \%$ at the tested doses of $100,80,60,40,20$ and $10 \mathrm{ppm}$, respectively as against $100 \%$ scavenging by the standard quercetin. It was observed that the extracted oil exhibited overall low antioxidant activity as compared to fruit matter or dry matter (135-144\%) being reported by Anjum et al.
(2013); Ahmad et al. (2014) and Ozusaglam and Kara koca (2013). However it can be assumed from the results that BGS oil possesses some antioxidant activity due to the oil will have a longer shelf life and it can be utilized in the preparation of value added food based products.

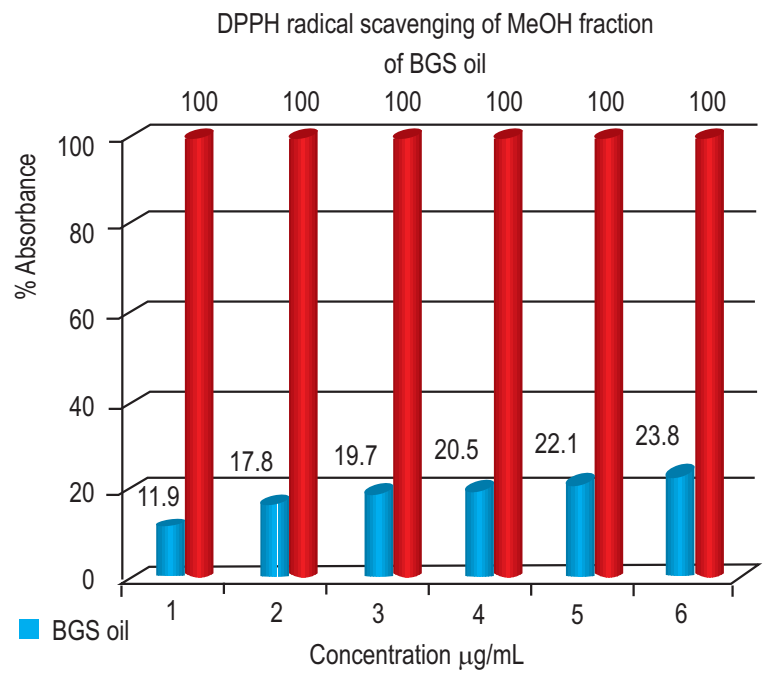

Fig. 2. Antioxidant DPPH free radical scavenging potential of BGS oil.

Table 4. Summary of the antibacterial activity of BGS oil

\begin{tabular}{lllll}
\hline \hline \multirow{2}{*}{ Concentration $(\mathrm{mg} / \mu \mathrm{L})$} & \multicolumn{3}{c}{ Zone of inhibition $(\mathrm{mm}) *$} \\
\cline { 2 - 5 } & Escherichia coli & Bacillus subtilis & Proteus mirabilis & Xynthomonas campestris \\
\hline 0.2 & $0.6 \pm 0.40$ & $1.2 \pm 0.67$ & $0.08 \pm 0.09$ & $0.53 \pm 0.37$ \\
0.4 & $2.1 \pm 0.08$ & $2.2 \pm 1.02$ & $0.16 \pm 0.05$ & $2.03 \pm 0.05$ \\
0.5 & $4.43 \pm 0.37$ & $2.86 \pm 1.34$ & $0.53 \pm 0.29$ & $3.26 \pm 0.20$ \\
0.6 & $5.96 \pm 0.05$ & $4.3 \pm 0.75$ & $1.13 \pm 0.26$ & $3.8 \pm 0.62$ \\
0.8 & $7.6 \pm 2.29$ & $6.96 \pm 0.05$ & $1.46 \pm 0.37$ & $7 \pm 0.81$ \\
Standard amoxicillin & $10.36 \pm 0.44$ & $8 \pm 0.81$ & $6.46 \pm 0.37$ & $10 \pm 0.08$ \\
DMSO & 0 & 0 & 0 & 0 \\
\hline \hline
\end{tabular}

$*=$ values are in terms of mean $\pm \mathrm{SD}$ of results done in triplicates.

Table 5. Summary of antifungal activities of BGS oil

\begin{tabular}{|c|c|c|c|c|}
\hline \multirow[t]{2}{*}{ Concentration $(\mathrm{mg} / \mu \mathrm{L})$} & \multicolumn{4}{|c|}{ Zone of growth $(\mathrm{mm})$} \\
\hline & Paecilomyces lilacinus & Phytium ultimum & Rhizopus stolonifer & Tricoderma harzianum \\
\hline 0.2 & $17.8 \pm 0.25$ & $18.96 \pm 0.78$ & $21.06 \pm 0.75$ & $24.9 \pm 0.53$ \\
\hline 0.4 & $12.5 \pm 0.41$ & $16.5 \pm 0.08$ & $20.7 \pm 0.08$ & $23.1 \pm 0.94$ \\
\hline 0.5 & $10.6 \pm 0.08$ & $15.9 \pm 0.05$ & $20 \pm 0.006$ & $20.86 \pm 0.65$ \\
\hline 0.6 & $9.5 \pm 0.08$ & $14.3 \pm 0.07$ & $18 \pm 0.006$ & $15.7 \pm 0.26$ \\
\hline 0.8 & $8.5 \pm 0.08$ & $9.6 \pm 0.08$ & $17.16 \pm 0.12$ & $12.46 \pm 0.37$ \\
\hline Miconazole & $19.3 \pm 0.82$ & $25.8 \pm 0.16$ & $22.7 \pm 0.88$ & $26.6 \pm 0.43$ \\
\hline DMSO & 0 & 0 & 0 & 0 \\
\hline
\end{tabular}


Antimicrobial assays of the BGS oil. The antibacterial and antifungal activities of Momordica charantia seed (BGS) oil against selected bacterial and fungal strains are presented in Tables 4-5. The data showed Escherichia coli and Xynthomonas campestris being the most sensitive bacterial strains against BGS oil as against the positive standard amoxicillin. Results of Escherichia coli are in agreement with the finding of Grover and Yadav (2004); Paul and Raychaudri (2010); Behara et al. (2010), Ahmad et al. (2014) and Sharma et al. (2011) showing the inhibitory ability of BGS oil for $E$. coli in the range of 2-12 mm. Similarly, antibacterial activity against Bacillus subtilis was according to the findings of Sharma et al. (2001) and Fritsch et al. (2007). The zone of inhibition against Proteus mirabilis and Xanthomonas campestris were similar to the finding of Leelaprakash (2011); Ahmad et al. (2014) and Ozusaglam and Karakoca (2013), respectively. Results of the antifungal activity of GBS against fungal strains showed the trend as follows:

Tricoderma harzianum $>$ Rhizopus stolonifer $>$ Phytium ultimum $>$ Paecilomyces lilacinus.

These results obtained for antifungal potential as the zone of growth of BGS oil were similar to the findings of Ahmad and Khan (2013) and Ozusaglam and Karakoca (2013) against Rhizopus and Trichoderma. Inhibitory activity for Paecilomyces and Pythium were in accordance with the finding of Anjum et al. (2013) and Ahmad et al. (2014). It can be concluded from the present findings that bitter melon seed oil possesses a very good antimicrobial potential against pathogenic bacteria and the studied fungal strains.

\section{Conclusion}

It can be concluded from the findings of the current study that BGS oil is a good source of dietary lipids due to its higher level of unsaturated fatty acids in seed oil and protein content in the seed cake. Due to its higher iodine value, low peroxide and free fatty acids properties it can be considered as a new and valuable source of edible oil having prolonged shelf life. The oil can have industrial utility in the manufacturing of margarine, soap production, and in paints and coating industry. Due to its good antimicrobial properties the oil can be used as antibacterial and antifungal agents in pharmaceutical preparations. It can also be utilized for blending with other conventional edible oils and in the preparation of nutraceuticals for health promotion.

\section{References}

Ahmad, K., Shireen, F., Mehreen, S.B. 2014. Phytochemical and medicinal investigation of Momordica charantia. Vegetos, 27: 86-89.

Ahmad, B., Khan, A.A. 2013. Antibacterial, antifungal and phyototoxic activities of Luffa cylindrica and Momordica charantia. Journal of Medicinal Plant Research, 7: 1593-1599.

Ali, M.A., Sayeed, M.A., Yesmin, M.S., Khan, M.A., Reza, M.S. 2008. Characteristics of seed oils and nutritional composition of seeds from different varieties of Momordica charantia Linn cultivated in Bangladesh. Czech Journal of Food Science, 26: 275-283.

Anjum, F., Shahid, M., Bukhari, A.S., Anwar, S., Latif, S. 2013. Study of quality characteristics and efficacy of extraction solvent/technique on the antioxidant activity of bitter gourd seed. Journal of Food Processing \& Technology, 4: 2-8.

AOAC, 2005. Official Methods of Analysis. Association of Official Analytical Chemists, $18^{\text {th }}$ edition, Washington DC, USA.

AOAC, 1990. Official Methods of Analysis. Association of Official Analytical Chemists, $5^{\text {th }}$ edition, pp. 910-928, Washington DC, USA.

AOAC, 1984. Official Methods of Analysis. Association of Official Analytical Chemists, $14^{\text {th }}$ edition, 110 pp., Arlington, VA, USA.

Assubaie, N.F., El-Garawary, M.M. 2004. Evaluation of some chemical constituents of Momordica charantia in Hofuf, Saudi Arabia. Journal of Biological Sciences, 4: 628-630.

Bakare, R.I., Magbagbeola, O.A., Akinwande, A.I., Okunowo, O.W. 2010. Nutritional and chemical evaluation of Momordica charantia. Journal of Medicinal Plants Research, 4: 2189-2193.

Behera, K.T, Behera, S., Bharati, K.L. 2010. Bitter gourd: Botany, horticulture, breeding. Horticulture Review, 37: 101-104.

Fritsch, T.R., McDermott, P.F., Shrycock, T.R., Walker, R.D., Morishita, T.Y. 2007. Agar dilution and disk diffusion susceptibility testing of Campylobacter. spp. Journal of Clinical Microbiology, 45: 27582759.

Grover, J.K., Yadav, S.P. 2004. Pharmacological actions and potential uses of Momordica charantia. A review. Journal of Ethnopharmacology, 93: 123132.

Harax, R., Hettiarachchy, N., Kennan, A., Chen, P. 
2010. Proximate composition and amino acid and mineral content of Momordica charantia -pericarp and seeds at different maturity stages. Food Chemistry, 122: 1111-1115.

Leelaprakash, G., Rose, C.J., Gowtham, B.M., Javvaji, K.P., Prasad, S.A. 2001. Invitro antimicrobial and antioxidant activity of Momordica charantia leaves. Pharmacophore, an International Research Journal, 2: 244-253.

Lucas, E.A., Dumancas, G.G., Smith, B.J., Clarke, S.L., Arjmandi, B.H. 2010. Health benefits of bitter melon (Momordica charantia), In: Bioactive Foods in Promoting Health, W. Ronald Ross and R. P. Victor (eds.), pp. 525-549, Academic Press, San Diego, USA.

Nyam, K.L., Tan, C.P., Lai, O.M., Long, K., Che-Mena, Y.B. 2009. Physicochemical properties and bioactive compounds of selected seed oils. LWT-Food Science and Technology, 42: 1396-140.

Ozusaglam, M.A., Karakoca, K. 2013. Antimicrobial and antioxidant activities of Momordica charantia from Turkey. African Journal of Biotechnology, 12: $1548-1558$.

Paul, A., Raychaudri, S.S. 2010 Medicinal uses and molecular identification of two Momordica charantia varieties-a review. Electronic Journal of Biology, 6: 43-50.

Prasantha, M.A.B., Permachandra, J.K., Amarasinghe, A.D.U.S. 2009. Composition, physical properties and drying characteristics of seed oil of Momordica charantia cultivated in Sri lanka. Journal of American Oil Chemists Society, 86: 27-32.

Rauf, A., Khan, A., Rasool, S., Shah, Z.A., Saleem, M. 2012. Invitro antifungal activity of three selected Pakistani medicinal plants. Middle-East Journal of Medicinal Plants Research, 1: 41-43.

Sharma, S., Tandon, S., Semwal, B., Singh, K.2011. Momordica charantia Linn: A comprehensive review on bitter remedy. Journal of Pharmaceutical Research and Opinion, 1: 42-47.

Sheikh, D.N., Zaman, S., Naqvi, B., Rafi, S.B., Ghulam, S. 1995. Studies of the antimicrobial activity of honey. Pakistan Journal of Pharmaceutical Sciences, 8: 51-62.

Tuan, P.A., Kim, J.K., Park, N.L., Park, S.U. 2011. Carotenoid content and expression of Phytoene synthesis and Phytoene desaturase genes in bitter melon (Momordica chrantia). Food Chemistry, 126: $1686-1692$.

Umamaheshwari, P., Naik, M.M. 2013. Comparative study of physico-chemical properties of bitter gourd seed oil with various other seed oils. International Journal of Advanced Scientific and Technical Research, 3: 435-440.

Yuwai, K.E., Rao, K.S., Kaluwin, C., Jones, G.P., Rivett, D.E. 1991. Chemical composition of Momordica charantia Linn Fruits. Jornal of Agriculture Food Chemistry, 39: 1762-1763. 